\title{
Guest editorial: theorizing the geoweb
}

\author{
Agnieszka Leszczynski • Matthew W. Wilson
}

Published online: 12 July 2013

(C) Springer Science+Business Media Dordrecht 2013

The general convergence of location with digital information communication technologies (ICTs) has brought about profound shifts in the content, forms, and practices that surround spatial media. In geography, these phenomena have been variously and alternately referred to as 'volunteered geographic information' (VGI) (Elwood et al. 2011; Goodchild 2007), 'neogeography' (Graham 2010; Turner 2006; Warf and Sui 2010; Wilson and Graham 2013a, 2013b), '(new) spatial media' (Crampton 2009; Elwood and Leszczynski 2012), and 'the geoweb,' (Elwood and Leszczynski 2011; Haklay et al. 2008; Scharl and Tochtermann 2007). Here, we prefigure 'the geoweb' as we consider it to account for both new materialities and new practices. Regardless of the neologism used to refer to these phenomena, they nevertheless present significant challenges to our disciplinary thinking about geographic information and technologies. Much of our early engagements

A. Leszczynski $(\bowtie)$

Department of Geography, Queen's University, Kingston, Canada

e-mail: agnieszka.leszczynski@queensu.ca

M. W. Wilson

Graduate School of Design, Harvard University,

Cambridge, Massachusetts, USA

M. W. Wilson

Department of Geography, University of Kentucky,

Lexington, Kentucky, USA

e-mail: matthew.w.wilson@uky.edu of the geoweb have been informed by the GIScience and Critical GIS traditions, which are ontologically and epistemologically committed to data regimes, practices, and technics associated with geographic information systems (GIS) as a singular or unique technological assemblage (for examples see Farman 2010; Guptill 2007; Miller 2006; Sui and Goodchild 2011; Sui 2008; Wilson 2009).

More recently, however, geographers have acknowledged that the rapid proliferation and diversification of spatial media, content forms, and praxes require new empirical, conceptual, and theoretical approaches to apprehend both the nature and implications of these transitions and materialities. This need for new approaches has been most saliently articulated in a 2008 special issue of GeoJournal devoted to VGI edited by Sarah Elwood (volume 72 issues 3-4) (Elwood 2008b). Contributors to this special issue highlighted the imperatives of reconceptualizing entrenched notions of 'the user' (Budhathoki et al. 2008); attending to the altered contexts of information curation (Flanagin and Metzger 2008); evaluating the effectiveness and appropriateness of existing frameworks - such as Feminist, Critical, and Participatory GIS - for 'reading' or engaging the geoweb (Elwood 2008a; Tulloch 2008); and, devising new metrics and/ or schemes for evaluating the validity and reliability of user-generated geographic information (Bishr and Mantelas 2008; Mummidi and Krumm 2008).

In response to this agenda-setting work, for which this journal importantly served as a venue, geographers 
moved beyond the descriptive bent of early engagements of the geoweb (see Leszczynski 2012a) towards the more important task of situating the geoweb by positioning its associated developments, materialities, subjectivities, and consumptive imperatives within the variegated socio-cultural, historical, political-economic, discursive, technical/material, and philosophical contexts of their emergence, production, commercialization, assimilation and naturalization. These efforts include a recent special issue of Environment and Planning A on Situating Neogeography (Wilson and Graham 2013a) which brings together contributions that address how the production and consumption of spatial content are bound up with the technological commercialization of these data and their instantiating mediums in myriad ways; a series of sessions devoted to 'Situating the Geoweb' organized by Agnieszka Leszczynski and Matthew Wilson at the 2010 AAG meetings in Washington, D.C.; and a 2009 special issue of Geoforum (Dodge and Perkins 2009) dedicated to explorations of the cultural, epistemological, and political consequences of the public availability of high-resolution commercial satellite imagery. Other contributions may also be considered as similarly contextualizing in nature, including, amongst others, work by Goodchild (2009) on the historical origins and significance of new map and spatial data production regimes; Zook and Graham (2007a, b, c) on the capitalist and commercial bases and biases of the digital production and representation of space(s) through the geoweb; Elwood and Leszczynski (2011) on privacy as a dimension for understanding the geoweb and its societal consequences; as well as Leszczynski (2012a) on the political economies of the geoweb.

This work towards 'situating,' however, is conditional-it describes contingent situations that define the technologies and practices that are constitutive of the assemblage(s) that we term 'geoweb.' Scholarship about the geoweb has not, however, yet made the leap to coming into conversation with a much broader series of literatures and discussions about digital culture. This is not an option for geographers but rather an urgent necessity. Critical GIS and GIScience have yet to fully move beyond this situational moment, an inertia underwritten, in part, by the status of GIS as the definitive technics of geography and the decades-long period during which no other technology or set of ontics challenged its supremacy, either technically or ontologically. The nature of the geoweb, however, demands that we enjoin much larger debates about digital technology and society-we can be isolationist and myopic no longer. The reasons for this are, we hope, obvious. The technical and pragmatic forces that are driving the phenomenon of the geoweb are not to be found within academic geography, but rather come out of the successive convergences of, on the one hand, information communication technologies (ICTs) with digital media and now location (Kelly 2013; Leszczynski 2012b; Wilson 2012), and of technoscience and (speculative forms of) capitalism on the other (Kinsley 2012; Leszczynski 2012a; Wilson 2012). Unlike GIS, furthermore, geoweb technologies are pervasive, substantive presences in people's daily lives, and their everyday deployments - and our everyday uses of these technological mediums - are rapidly altering the ways in which we interact with not only one another but indeed interact with, experience, and build attachments to space/place. This convergence of spatial information and technologies with digital media, and the consequent imbrication of geoweb technologies, affordances, and information artifacts into everyday sociality means that 'the geoweb' cannot be understood, apprehended, or engaged in isolation from other (new) media emergences, materialities, subjectivities, and practices. To understand the ways in which spatial content and technics are (inter)mediating forces that signal deep changes in the nature of the societytechnology-nature-space relationship, we need to be in conversation with interventions that are similarly engaging these pronounced shifts in disciplines such as the digital and spatial humanities, science and technology studies, sociology, (new) media studies, computing science, international studies, and aesthetics, amongst others. Being in conversation with these literatures and disciplinary perspectives furthermore provides us an opportunity to speak back to dominant ideas about the effects of pervasiveness and mediation, particularly as it concerns naïve pronouncements of digital ICTs and the Internet as signaling and ushering in the death and/or irrelevance of space (see Graham 2013 for discussion)—something geographers are uniquely positioned to do.

By 'theorizing the geoweb,' then, we intend a dual meaning of 'theorizing': as bringing theory into the geoweb/the geoweb speaking to theory; and as a responsibility to difference and diversity (McDowell 2000). The first-writing theory into the geoweb/ 
writing the geoweb into theory-most directly speaks to the challenges and necessity of engaging in broader debates about the role and status of pervasive technologies in society. This asks that we consider what theories of digitality, media, and technology and society have to tell us about the geoweb, and, more specifically, what it is about the geoweb these established theories help us to understand. Reversing the equation, this also asks for an evaluation of how the geoweb, and in particular its explicit spatiality, informs existing theories of technology, society, space, and nature. The second of these definitions of theory-as a responsibility to difference and diversity, which McDowell (2000) reminds us is the role of theory in geography-holds us accountable to examining and accounting for how the geoweb, and the ways in which we enroll its constituent materialities, prefigure, encode, reify, and (re)produce 'otherness,' inequality, and exclusion along multiple axes.

Since the setting of the geoweb research agenda five years ago in the 2008 VGI special issue of GeoJournal, geographers have begun to offer interventions in both of these veins of 'theorizing.' For example, geographers have devised and leveraged new theoretical concepts-including 'conspicuous mobility' (Wilson 2012), 'prosumption' (Haklay et al. 2008), and 'DigiPlace' (Zook and Graham 2007a, b, c) — that help us understand the new forms of subjectivity, consumption, being-in-the-world, and digitally-mediated nature of space/place that are both engendered by, and generative of, the geoweb. Elsewhere, geographers have attended to the ways in which the geoweb (re)produces difference and inequalities in ways that are themselves inherently geographical (Crutcher and Zook 2009; Graham et al. 2012a, b; Graham and Zook 2013).

To further stimulate theoretical engagements of the geoweb, and to provide a forum for the discussion and exchange of theoretical interventions vis-à-vis the geoweb and technology, we organized a series of sessions at the 2012 AAG meetings held in New York. The papers in this collection represent the contributions of the participants of those successful back-toback sessions. As with the forays into theorizing the geoweb identified above, they speak to both of the meanings of 'theorizing' we identify herein. The first three papers, by Bauch (2013), Bittner et al. (2013), and Lin (2013), represent efforts at reading the geoweb through the lenses of established social theory, and writing the geoweb into our socio-theoretical thinking about technology, society, space and nature. The latter two papers, by Thatcher (2013) and Stephens (2013), conversely attend to the inequalities of the geoweb along the lines of race and gender, respectively.

Nicholas Bauch draws on the object-oriented philosophy of Graham Harman to grapple with the extra-materiality of sensory biological data that become (perceived as) disembodied as they are transmitted over Wireless Body Area Networks (WBANs). He argues that thinking of these data and their transmission in terms of their extensibility or extension into space is instructive towards helping geographers not only account for the spatiality of the geoweb, but also to contend with "how, and where, the [g]eoweb exists as a technological assemblage of objects and information". Bittner, Glasze and Turk similarly theorize the geoweb as an assemblage, engaging cartographic representations generated through geoweb platforms, which they term 'web 2.0 cartographies,' through actor-network theory. They argue that while actor-network theory (ANT) is useful for helping us understand the various human, technical, and institutional actors that constitute the assemblage(s) comprised by and through any geoweb cartographic representation, ANT describes only existing relations-the actors and practices that are identifiable in the end product—while marginalizing the social relations that did not 'make it into,' or are not captured by, the final representation. To this end, working through the example of the Palestine Crisis Map built using the Ushahidi engine, they draw on Laclau and Mouffe's concept of the political to help us theorize how such social relations become 'sedimented' or 'fixed,' and propose a methodology for tracing and identifying the other actors, practices, and intersectionalities that are excluded from the visual products that are delivered to us as definitive, hegemonic accounts of social reality.

Like Bittner, Glasze, and Turk's intervention, Lin's paper highlights the importance of networks for understanding the geoweb, although for her, the concept of the network is useful in helping us to (re)theorize the nature of 'the public' or 'publics' that engage/are engaged by geoweb technologies and platforms. Drawing on her work on the geoweb in China, Lin argues that in order to understand how publics are formed and brought together through webbased spatial platforms, 'publics' must be theorized as 
inherently 'networked,' i.e., as "linked sets of social and technological developments associated with the growing engagement of digitally networked media". She concludes by fleshing out some of the implications of networked publics for collective action and mobilization around and through web-based spatial media.

Through reference to Heideggerian and Marcusian theories of technology and society, Thatcher examines how specific instances of geoweb applications and services-in this case, Microsoft's Pedestrian Route Production patent, popularly known as the "avoid Ghetto GPS" — not only algorithmically prefigure raced and classed social inequalities, but indeed actively produce spatial futures that are raced and classed, thereby perpetuating and extending existing socio-spatial inequalities forward in time and space. Continuing with this emphasis on how exclusion along social axes of difference is (re)produced through the geoweb, the final paper in this collection, by Monica Stephens, investigates the trenchant gender divide in practices of contributing user-generated geographic information to the geoweb. On the basis of an empirical survey, she demonstrates that this divide exists not only in terms of which gender is more likely to contribute (men are far more dominant), but that the bias also extends to and is perhaps even more pronounced at the level of purportedly democratic data legitimation practices (e.g., OpenStreetMap editors who vote on the validity and legitimacy of usergenerated contributions to the initiative). The gender imbalance amongst the editorship of several large crowdsourced mapping initiatives results in men serving as the gatekeepers of knowledge. The effect is the masculinist (re)production of space, in which male spaces are prefigured and feminized spaces are left off the map entirely.

In bringing this special issue together, we intend to promote an engagement of the geoweb through varied theoretical lenses that bring us (geographers) more immediately into contemporary debates about the interface between society and technology more broadly. Additionally, we aim to demonstrate the ways in which we can add to and further these discussions by insisting on the ways in which society/ technology interactions are always interactions between society, technology, and space/place. The interventions profiled here are not exhaustive of attempts at theorizing the geoweb, but rather constitute examples of what such a theorizing can look like in practice, and of the kinds of questions that an attention to theory can provoke towards helping us better apprehend the nature of the changes (in socio-spatiotechnical relations) being wrought through the geoweb. In closing, we would like to thank Dan Sui for graciously inviting us to organize and co-edit this special issue, and for offering GeoJournal as a volume for the conversations held herein. We are furthermore grateful to the authors for their manuscripts, as we are to all of the presenters who participated in our coorganized AAG sessions in New York in February of 2012. And, or course, we are indebted to the reviewers for their invaluable service towards helping this special issue come together.

\section{References}

Bauch, N. (2013). Extensible, not relational: Finding bodies in the landscape of electronic information and wireless body area networks. GeoJournal, (this issue).

Bishr, M., \& Mantelas, L. (2008). A trust and reputation model for filtering and classifying knowledge about urban growth. GeoJournal, 72(3-4), 229-237.

Bittner, C., Glasze, G., \& Turk, C. (2013). Tracing contingencies-analyzing the political in assemblages of web 2.0 cartographies. GeoJournal, (this issue).

Budhathoki, N. R., Bruce, B. C., \& Nedovic-Budic, Z. (2008). Reconceptualizing the role of the user of spatial data infrastructure. GeoJournal, 72(3-4), 149-160.

Crampton, J. W. (2009). Cartography: Maps 2.0. Progress in Human Geography, 33(1), 91-100.

Crutcher, M., \& Zook, M. A. (2009). Placemarks and waterlines: Racialized cyberscapes in post-katrina Google earth. Geoforum, 40(4), 523-534.

Dodge, M., \& Perkins, C. (2009). Editorial: The 'view from nowhere'? Spatial politics and cultural significance of highresolution satellite imagery. Geoforum, 40(4), 497-501.

Elwood, S. (2008a). Volunteered geographic information: Future research directions motivated by critical, participatory, and feminist GIS. GeoJournal, 72(3-4), 173-183.

Elwood, S. (2008b). Volunteered geographic information: Key questions, concepts and methods to guide emerging research and practice. GeoJournal, 72(3-4), 133-135.

Elwood, S., Goodchild, M. F., \& Sui, D. Z. (2011). Researching volutneered geographic information: Spatial data, geographic research, and new social practice. Annals of the Association of American Geographers, 102(3), 571-590.

Elwood, S., \& Leszczynski, A. (2011). Privacy, reconsidered: new representations, data practices, and the geoweb. Geoforum, 42(1), 6-15.

Elwood, S., \& Leszczynski, A. (2012). New spatial media, new knowledge politics. Transactions of the Institute of British Geographers,. doi:10.1111/j.1475-5661.2012.00543.x. 
Farman, J. (2010). Mapping the digital empire: Google earth and the process of postmodern cartography. New Media \& Society, 12(6), 869-898.

Flanagin, A. J., \& Metzger, M. J. (2008). The credibility of volunteered geographic information. GeoJournal, 72(3-4), 137-148.

Goodchild, M. (2007). Citizens as sensors: The world of volunteered geography. GeoJournal, 69(4), 211-221.

Goodchild, M. F. (2009). GeoJournal plenary lecture: Citizens as censors: The world of volunteered geography. Paper presented at the Association of American Geographers Annual Meeting, Las Vegas, NV, 22-27.

Graham, M. (2010). Neogeography and the palimpsests of place: Web 2.0 and the construction of a virtual earth. $T i$ jdschrift voor economische en sociale geografie, 101(4), 422-436.

Graham, M. (2013). Geography/Internet: Ethereal alternate dimensions of cyberspace or grounded augmented realities? The Geographical Journal,. doi:10.1111/geoj.12009.

Graham, M., Hale, S., \& Stephens, M. (2012a). Digital divide: The geography of internet access. Environment and Planning A, 44(5), 1009-1010.

Graham, M., Stephens, M., Hale, S. A., \& Kono, K. (2012). Geographies of the world's knowledge. Oxford: Oxford Internet Institute/Convoco!

Graham, M., \& Zook, M. (2013). Augmented realities and uneven geographics: Exploring the geo-linguistic contours of the web. Environment and Planning A, 45(1), 77-99.

Guptill, S. C. (2007). GIscience, the NSDI, and Geowikis. Cartography and Geographic Information Science, 34(2), 165-166.

Haklay, M., Singleton, A., \& Parker, C. (2008). Web mapping 2.0: The neogeography of the geoweb. geography. Compass, 2(6), 2011-2039.

Kelly, M. J. (2013). The emergent urban imaginaries of geosocial media. GeoJournal, 78(1), 181-203.

Kinsley, S. (2012). Futures in the making: Practices to anticipate 'ubiquitous computing'. Environment and Planning A, 44(7), 1554-1569.

Leszczynski, A. (2012a). Situating the geoweb in political economy. Progress in Human Geography, 36(1), 72-89.

Leszczynski, A. (2012b). Thinking the Geoweb: Political economies, 'neo'geographies, and spatial media. $\mathrm{PhD}$ Dissertation. Seattle, WA: University of Washington.

Lin, W. (2013). VGI and networked publics? Politics of everyday mapping and spatial narratives. GeoJournal, (this issue).

McDowell, L. (2000). Understanding diversity: The problem of/ for theory. In R. J. Johston, P. J. Taylor, \& M. Watts (Eds.), Geographies of Global Change (pp. 280-294). Oxford: Blackwell.
Miller, C. C. (2006). A beast in the field: The Google maps mashup as GIS/2. Cartographica, 41(3), 187-199.

Mummidi, L. N., \& Krumm, J. (2008). Discovering points of interest from users' map annotations. GeoJournal, 72(3-4), 215-227.

Scharl, A., \& Tochtermann, K. (2007). The geospatial web: how geobrowsers, social software and the Web 2.0 are shaping the network society. London: Springer.

Stephens, M. (2013). Gender and the geoweb: Divisions in the production of user-generated cartographic information. GeoJournal, (this issue).

Sui, D. Z. (2008). The wikification of GIS and its consequences: Or Angelina Jolie's new tattoo and the future of GIS. Computers, Environment and Urban Systems, 32(1), 1-5.

Sui, D., \& Goodchild, M. (2011). The convergence of GIS and social media: Challenges for GIScience. International Journal of Geographic Information Science, 25(11), 1737-1738.

Thatcher, J. (2013). Avoiding the Ghetto through hope and fear: An analysis of immanent technology using ideal types. GeoJournal, (this issue).

Tulloch, D. D. (2008). Is VGI participation? From vernal pools to video games. GeoJournal, 72(3-4), 161-171.

Turner, A. (2006). Introduction to Neogeography. Sebastopol, CA: O'Reilly.

Warf, B., \& Sui, D. (2010). From GIS to neogeography: Ontological implications and theories of truth. Annals of GIS, 16(4), 197-209.

Wilson, M. W. (2009). Towards a Genealogy of Qualitative GIS. In M. Cope \& S. Elwood (Eds.), Qualitative GIS (pp. 156-170). Thousand Oaks, CA: Sage.

Wilson, M. W. (2012). Location-based services, conspicuous mobility, and the location-aware future. Geoforum, 43(6), 1266-1275.

Wilson, M. W., \& Graham, M. (2013a). Neogeography and volunteered geographic information: A conversation with Michael Goodchild and Andrew Turner. Environment and Planning A, 45(1), 10-18.

Wilson, M. W., \& Graham, M. (2013b). Situating neogeography. Environment and Planning A, 45(1), 3-9.

Zook, M., \& Graham, M. (2007a). From Cyberspace to DigiPlace: Visibility in an Age of Information and Mobility. In H. Miller \& H. Rheingold (Eds.), Societies and Cities in the Age of Instant Access (pp. 231-244). Dordrecht: Springer.

Zook, M. A., \& Graham, M. (2007b). The creative reconstruction of the internet: Google and the privatization of cyberspace and digiplace. Geoforum, 38(6), 1322-1343.

Zook, M. A., \& Graham, M. (2007c). Mapping digiplace: Geocoded internet data and the representation of place. Environment and Planning B: Planning and Design, 34(3), 466-482. 